\title{
32. LA RESPONSABILIDAD POLÍTICA DEL GOBIERNO
}

\author{
PILAR MELLADO PRADO
}

Profesora Titular de Derecho Constitucional

UNED 


\section{SUMARIO}

I. LA RESPONSABILIDAD POLITICA SOLIDARIA.-1. ${ }^{\circ}$ La confianza parlamentaria se otorga exclusivamente al Presidente del Gobierno. 2. ${ }^{a}$ El Título $V$ de la Constitución prevé un régimen parlamentario "racionalizado". 3. " Las llamadas "mociones de reprobación" no son mecanismos de exigencia de responsabilidad política individual. II. LA CUESTIÓN DE CONFIANZA: ARTS. 112 Y 114.1 CE.-1. Alcance constitucional de la cuestión de confianza. 2. Plazo de enfriamiento o reflexión previo a la votación de la cuestión de confianza. 3. La cuestión de confianza y el derecho de disolución. III. LA MOCIÓN DE CENSURA: ARTS. 113 Y 114.2.1. Plazo de enfriamiento o reflexión. 2. Sanción a los firmantes de una moción de censura. 


\section{LA RESPONSABILIDAD POLÍTICA DEL GOBIERNO}

POR

PILAR MELLADO PRADO

Profesora Titular de Derecho Constitucional

UNED

\section{LA RESPONSABILIDAD POLITIICA SOLIDARIA: \\ Art. $108 \mathrm{CE}$}

Siguiendo una vieja convención constitucional británica, el artículo 108 afirma expresamente el principio de la responsabilidad política solidaria: «El Gobierno responde solidariamente en su gestión política ante el Congreso de los Diputados».

Como es sabido, la responsabilidad política solidaria significa $-y$ ha significado sobre todo en el pasado-que por las decisiones adoptadas colegialmente en el Consejo de Ministros responden todos sus miembros; y significa también - sobre todo en la actualidad-que todo el Gobierno responde por las decisiones de uno solo de sus miembros, porque hoy aquéllas son imputables a la misma línea política, de modo que, en principio, el Parlamento puede remover a todo el Gobierno a causa de cualquier decisión de alguno de sus componentes, aun cuando no haya sido adoptada en Consejo de Ministros. De esta forma, la solidaridad transforma en colectiva la posible responsabilidad política individual.

La actuación del principio formal de la solidaridad gubernamental se concreta tan sólo cuando se basa realmente en la unidad del Gobierno, unidad que el ordenamiento español tutela, confiriendo al órgano gubernamental una definida estructura unitaria y regulándolo de tal forma que 
su acción pueda explicarse de manera uniforme. El Gobierno, así, se ve obligado a seguir la línea política formulada por su Presidente en la investidura, es decir, en la votación inicial de confianza parlamentaria. Otro presupuesto básico de la responsabilidad política solidaria es la formación de un Gobierno políticamente homógeneo, presupuesto que viene garantizado en el art. 100 de nuestra Constitución, en virtud del cual es el Presidente del Gobierno quien elige y propone el nombramiento de sus ministros al Rey.

Al haber establecido el título $\mathrm{V}$ un sistema de relaciones GobiernoCortes presidido por el llamado "Principio de Canciller» del que se deriva un fuerte liderazgo en favor del Presidente del Gobierno, la responsabilidad de los ministros y su solidaridad se subsume, de hecho, en la responsabilidad del Presidente, que es quien propone su nombramiento y cese. En definitiva, la relación de confianza del Gobierno con el Congreso de los Diputados -única Cámara que participa en el proceso inicial de formación del Gobierno y que puede exigirle responsabilidad política- aparece cristalizada en la figura del Presidente del Gobierno, lo cual no hace desaparecer la solidaridad gubernamental sino que, al contrario, pone en marcha su funcionamiento ya que el cese o dimisión del Presidente implica el de todo el Gobierno (Art. $101 \mathrm{CE}$ ).

A pesar de que en los últimos años un importante sector doctrinal ha defendido inteligentemente la existencia en nuestra Constitución de una responsabilidad política individual de los ministros ante el Congreso de los Diputados en base a una interpretación sistemática de los artículos 64.2 y 98.2, y que este sería el momento oportuno, en su caso, para incluir expresamente aquélla en el artículo 108, propongo mantener su redacción actual por varias razones que expongo brevemente a continuación.

\section{La confianza parlamentaria se otorga exclusivamente al Presidente del Gobierno}

A mi juicio, la responsabilidad solidaria del Gobierno, prevista en el artículo 108 y la consiguiente exclusión de la responsabilidad política individual de sus miembros, es coherente con la forma de otorgar la confianza parlamentaria a través de la votación de investidura, que se otorga por el Congreso de los Diputados al Presidente y a su programa, no a su equipo ministerial (art. 99 CE). Así pues, si la confianza inicial de la Cámara Baja sólo se expresa respecto del Presidente del Gabinete y no de sus miembros - futuros, por lo demás- resultaria algo más que incongruente permitir al Congreso retirar a los ministros una confianza que nunca les ha 
otorgado al exigirles responsabilidad política individualmente. Recordemos que en Italia se prevé la responsabilidad política individual porque la investidura la recibe todo el Gobierno y no únicamente su Presidente.

Los miembros del Gobierno no necesitan de la confianza del Congreso de los Diputados ni para su nombramiento, ni para su permanencia en el Gobierno. La responsabilidad de proponer su nombramiento y su separación recae exclusivamente sobre el Presidente del Gobierno. Puede afirmarse por ello que existe una estrecha dependencia de los ministros respecto a su Presidente, es decir, la relación de confianza se establece entre el Presidente y sus ministros, no entre éstos y el Congreso. De ahí que esa estrecha dependencia se traduzca en una subordinación funcional de la actividad del equipo gubernamental a la orientación política de su Presidente. $Y$ precisamente de esa dependencia se deriva una delicada función presidencial: la de controlar -en el sentido múltiple de limitar, verificar e intervenir- la gestión de los ministros. Esta función de control no viene expresamente atribuida por la Constitución al Presidente del Gobierno, sino que se infiere claramente de la facultad que a éste se atribuye de proponer su nombramiento y separación.

En mi opinión, los ministros descansan en la confianza del Presidente del Gobierno, quien los elige y separa efectivamente. En consecuencia, de esa relación de confianza nace una "responsabilidad política» de los miembros del Gobierno de cara a su Presidente, que sólo es exigible por éste y no por el Congreso de los Diputados. Se trataría de una uresponsabilidad política intraorgánica» a la que se refiere el artículo $98.2 \mathrm{CE}$ cuando fija la responsabilidad directa de los miembros del Gobierno por su gestión ministerial. Los ministros, pues, permanecen en el Gabinete en tanto en cuanto conservan la confianza del Presidente y cesan cuando esa confianza presidencial se extingue.

\section{2." El Título $\mathrm{V}$ de la Constitución prevé un régimen parlamentario "racionalizado»}

Otra razón que abunda en mi negativa a incluir la responsabilidad política individual de los ministros ante el Congreso viene dada por la especial configuración del régimen parlamentario en nuestro texto constitucional. Admitir esa responsabilidad individual sería radicalmente incongruente con la forma de parlamentarismo "racionalizado» consagrado en el Título V de la Constitución.

Es evidente que si bien la exigencia de responsabilidad individual 
encaja perfectamente en los entramados del parlamentarismo clásico, resulta, sin embargo, mucho más difícil introducirla en los esquemas del régimen parlamentario "racionalizado", que al consagrar de forma excluyente la responsabilidad política solidaria crea un factor más de estabilidad gubernamental. Precisamente, si es a través de esa "racionalización" del parlamentarismo como nuestro texto fundamental persigue Gobiernos fuertes y estables, sería más que discutible permitir al Congreso de los Diputados encausar constantemente a los ministros individualmente, perturbando asi de formar permanente la cohesión del órgano ejecutivo.

\section{Las llamadas «mociones de reprobación" no son mecanismos de exigencia de responsabilidad política individual}

Las "mociones de reprobación" contra la gestión de determinados ministros, presentadas en el Congreso de los Diputados, en septiembre de 1981, abril y octubre de 1984, pretendían censurar a determinados miembros del Gobierno, haciendo equivalentes los términos censurar y reprobar. Si bien puede admitirse que los efectos politicos de aquellas mociones son visibles ya que su aprobación hubiera constituido una seria advertencia al Gobierno y a su Presidente, y que no encuentro ningún obstáculo que impida afirmar su constitucionalidad como simples actos de control parlamentario que no provocan ipso iure la dimisión del ministro afectado, no considero admisible aceptar una censura encubierta bajo la forma de una "moción de reprobación" dirigida directamente contra uno o varios ministros.

Querría añadir un elemento más a favor de esta tesis, y es la posibilidad de que en el Senado se presenten también "mociones de reprobación». Es sabido que si bien el Senado no está legitimado para exigir responsabilidad política al Gobierno, puede, sin embargo, controlar su actividad a través de una serie de mecanismos entre los que se encuentran las mociones a que pueden dar lugar las interpelaciones.

En mi opinión, la reprobación por las Cámaras de la política de los ministros, individualmente considerados, no tiene más efecto que el puramente moral, que puede afectar, en su caso, a la imagen que ante la opinión pública tuviera el ministro reprobado como hombre político. La posible votación favorable a la reprobación no obligaría al ministro afectado a dimitir; que éste se mantenga o no en el cargo no dependerá de la voluntad del Congreso (salvo que se aprobara una moción de censura) sino de la prudencia y conveniencia presidencial. 


\section{LA CUESTIÓN DE CONFIANZA: ARTS. 112 Y 114.1 CE}

\section{Alcance constitucional de la cuestión de confianza}

La fórmula del art. 112 es algo restrictiva en cuanto al alcance de la cuestión de confianza, ya que el Presidente del Gobierno sólo puede plantearla, oído el Consejo de Ministros, sobre una modificación de su programa o una declaración de política general. Queda excluida así la posibilidad de plantearla vinculada a un texto legislativo o a una parte de su articulado, de tal manera que el otorgamiento de la confianza suponga la aprobación, sin discusión, de dicho texto o de alguna de sus disposiciones.

Hay que admitir, por una parte, que al restringuir expresamente el ámbito de la cuestión de confianza se protege la independencia del Congreso de los Diputados en el ejercicio de sus atribuciones políticas y normativas, evitando así ser sometido a la presión (por no decir al chantaje) de arriesgarse a provocar una crisis de la que podría salir mal parado en caso de discrepar con alguna iniciativa gubernamental.

Pero, por otra parte, al limitar su alcance, se priva a la cuestión de confianza de una de sus potencialidades más efectivas, y por ende, al Gobierno de una de sus armas tradicionales para el desarrollo integral de su política.

En mi opinión, la exclusión que se hace en el art. 112 CE de la posibilidad -existente en otros ordenamientos constitucionales europeos de los que se siente directamente heredera nuestra Constitución de 1978- de plantear la cuestión de confianza ligada a un proyecto de ley parece incongruente con el sistema parlamentario fuertemente racionalizado adoptado en el Título V, y cuyo objetivo primordial es garantizar sobremanera la estabilidad gubernamental.

Entiendo los recelos que este mecanismo despierta, por cuanto su constitucionalización pudiera suponer en esos determinados casos la exclusión del Senado del procedimiento legislativo, $y$ también que en determinados supuestos podría convertirse en un medio para despreciar constantemente la opinión de las minorias. Sin embargo, considero que el artículo 112 debería incluir la posibilidad antes aludida, ya que no se trata de un poder exagerado en manos del Gobierno pues éste compromete su responsabilidad política ante el Congreso, y le permite utilizarla para reforzar su posición política. De lo contrario se resta a la cuestión de confianza una importante dosis de utilidad práctica. 


\section{Plazo de enfriamiento o reflexión previo a la votación de la cuestión de confianza}

El Reglamento del Congreso de los Diputados dispone que, finalizado el debate, la propuesta de confianza será sometida a votación, si bien entre la presentación y la votación debe mediar un plazo mínimo de 24 horas (Art. 174.4). Este plazo mínimo que la Constitución no menciona es un plazo de los llamados "de reflexión o enfriamiento" enmarcado en la línea de "racionalización" de las prácticas parlamentarias. La exigencia de este plazo mínimo debería ser incluido en el texto constitucional y aumentar a 48 horas - el previsto por el Reglamento es demasiado breve- siguiendo lo dispuesto en el art. 68.2 de la Ley fundamental de Bonn.

\section{La cuestión de confianza y el derecho de disolución}

En este punto querría proponer una posible adición al art. $115 \mathrm{CE}$ en virtud de la cual el Presidente del Gobierno que plantee una cuestión de confianza no pueda, durante su tramitación, y por supuesto, antes de proceder a la votación de aquélla, proponer al Rey la disolución del Congreso o de las Cortes Generales de conformidad con el art. 115.1 CE, ante la intuición de un previsible resultado adverso. Políticamente sería un fraude a la Cámara de representación popular que, una vez consultada sobre sí otorga o deniega su confianza, está en el legítimo derecho de pronunciarse.

\section{LA MOCIÓN DE CENSURA CONSTRUCTIVA: ARTS. 113 Y 114.2}

\section{Plazo de enfriamiento o reflexión}

El art. 113.3 CE prevé que "la moción de censura no podrá ser votada hasta que transcurran cinco días desde su presentación". Esta congelación temporal se produce, en el caso español, respecto al comienzo de la votación y no al de la discusión o debate, como ocurre en Francia y Alemania.

En mi opinión este plazo de cinco días -que sigue el precedente del art. 64 de la Constitución española de 1931- es excesivo porque la incertidumbre política que provoca una moción de censura debe ser disipa- 
da cuanto antes. Recordemos que ya Azaña, siendo Presidente del Gobierno, puso de manifiesto la disfuncionalidad de un plazo tan dilatado, con ocasión de la presentación en las Cortes de una moción de censura contra su Gobierno por el asunto de Casas Viejas. Azaña adujo entonces que su Gobierno no podía resistir tal situación de interinidad y se anticipó a la votación de la moción planteando una cuestión de confianza.

Además, dado el carácter constructivo que en nuestro texto constitucional tiene la moción de censura, es menos necesario ese plazo tan largo que en otros ordenamientos, porque la necesidad de llegar a un acuerdo sobre un candidato alternativo a la Presidencia del Gobierno para poder plantearla, evita ya el peligro de las votaciones impremeditadas, irreflexivas o caprichosas.

Propongo, por tanto, una modificación del art. 113.3 en virtud de la cual "la moción de censura no podrá ser discutida y votada hasta que transcurran al menos $\mathbf{4 8}$ horas desde su presentación".

\section{Sanción a los firmantes de una moción de censura}

Uno de los efectos del rechazo de la moción de censura previstos por nuestro texto constitucional es la imposición a sus signatarios de una penalización, consistente en no poder firmar otra durante el mismo período de sesiones (art. 113.4 CE). En mi opinión, los efectos de este precepto sancionador -inspirado en el art. 49.2 de la Constitución francesa de 1958- son muy limitados, ya que un período de sesiones es un plazo muy breve. El carácter constructivo de la moción de censura, los requisitos formales que la rodean y el actual sistema de partidos español impiden pensar en un uso excesivo de este mecanismo de exigencia de responsabilidad política que parece más bien limitado en su utilización a ser un instrumento de proyección de las críticas a la gestión política del Gobierno hacia la opinión pública. Por todo ello propongo la supresión de la cláusula sancionadora prevista en el art. 113.4 que difícilmente puede tener una aplicación real, y que en caso de tenerla, carece de efectos relevantes. 